\title{
A SEIRS Model of Tuberculosis Infection Model with Vital Dynamics, Early Treatment for Latent Patients and Treatment of Infective
}

\author{
Sulayman Fatima ${ }^{\mathrm{a}}$, Amit Mishra ${ }^{\mathrm{b}}$ \\ ${ }^{a}$ Department of Mathematical Sciences, Ibrahim Badamasi Babangida University Lapai +234 , Nigeria \\ ${ }^{b}$ Department of Computer Sciences, Baze University, Abuja +234, Nigeria
}

Received: 01 November 2019; Accepted: 15 December 2019; Published: 08 June 2020

\begin{abstract}
Tuberculosis is one of the most destructive bacteria in human being and the second cause of mortality after HIV/AIDS in the whole world. In this research work, a SEIRS of mathematical model for the transmission of tuberculosis incorporating vital dynamics, early therapy of patient with tuberculosis were studied and a model for treatment of infective as controls was developed. The effective reproduction number and the disease-free equilibrium was also analysed for the stability. The results revealed that the two controls reduce effective number below unity. Furthermore, it shows that early therapy of patient with tuberculosis is more effective in mitigating the spread of tuberculosis burden.

Index Terms: Tuberculosis Transmission; Control Strategy; Disease Free Equilibrium; Effective Reproduction Number; Stability.

(C) 2020 Published by MECS Publisher. Selection and/or peer review under responsibility of the Research Association of Modern Education and Computer Science
\end{abstract}

\footnotetext{
* Corresponding author.
}

E-mail address: 


\section{Introduction}

Tuberculosis (TB) is an airborne disease caused by Mycobacterium tuberculosis (Mtb) bacterial [10]. It has been known since 1000 B.C., so it not a new disease. About 3 million death worldwide attributed to tuberculosis every year [4].

Since TB is a disease of respiratory transmission, optimal conditions for transmission include:

- Overcrowding

- Poor personal hygiene

- Poor public hygiene.

Most cases of TB infection are in developing countries [7]. Transmission of TB result through the tiny droplets released into air via cough and sneezes from one person to another, it's a communicable disease. The bacteria usually attack the lungs.

In addition, according to the World Health Organization, one-third of the world's population is infected, either latently or actively, with tuberculosis [1]. There are more cases of tuberculosis in the world today than in previous time in human [17].

Tuberculosis: Signs and Symptoms

. Cough that lasts for more than 2 weeks

. Fever

. Night sweats

. Feeling weak \& 8red

. Losing weight (without trying)

. Loss of appetite

. Chest pains

. Coughing up blood

The study of tuberculosis transmission dynamics has been of great interest to both applied mathematicians and biologists because of its universal threat to humanity [25].

A number of theoretical studies have been carried out on the mathematical modelling of tuberculosis transmission dynamics $[1,5,9,11-15,17,18,24,25]$.

[2] modeled tuberculosis transmission that incorporates treatment and chemoprophylaxis. They assumed that latency infected individuals developed active tuberculosis disease as a result of endogenous re-activation, exogenous reinfection and disease relapse. Their results showed that treatment of infective is more effective in the first years of implementation as treatment results in clearing active TB immediately and there after chemoprophylaxis will do better in controlling the number of infective due to reduced progression to active TB.

The main principal aim of the current work is to improved on the SIR model of tuberculosis initially studied by [25]. TB have a long incubation period or latent at which an individuals is infected but cannot spread the infection [26,27]due to the long incubation period exposed class has been incorporated in to the model by [25].

By considering the work of authors mentioned above, we developed and analyzed a new mathematical model of tuberculosis infection to complements and extend their works by incorporating the following factors that are very important in the transmission of tuberculosis infection.

- Vital dynamics with unequal birth rate and death rate

- Temporary immunity for describing the spread of infectious disease

- $\quad$ Standard incidence rate

- $\quad$ Disease induced death due to tuberculosis

- Treatment of both latency and infective.

The reminder of this paper is organized as follows. In section (2), we formulate the model (3) we analysed the model to obtained the effective basic reproduction number and establishing the condition for local and global stability of the disease free equilibrium of the model and finally we discuss the results in section (4). 


\section{Material and Method}

A mathematical model for tuberculosis infection is developed by making improvement on the previous models as actual source and can be seen from figure 1 .

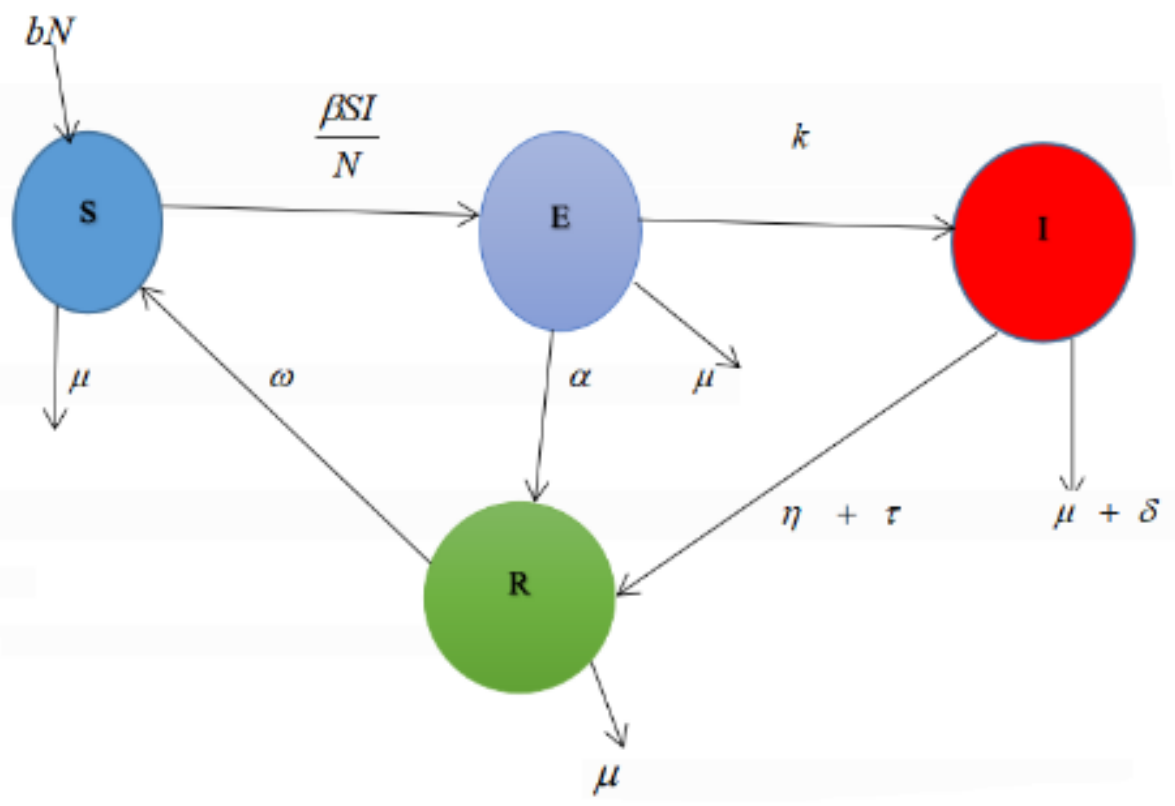

Fig. 1: Schematic diagram for Tuberculosis transmission with early treatment of latent patient and treatment of infection.

\subsection{Model Assumption}

A model the spread of tuberculosis was developed with the following assumption.

- Homogeneous mixing, susceptible individuals acquire tuberculosis infection following contact rate with an infective individual

- Treatment are offered to both latency infected and infectious

- The infection does not confer immunity to the cure and as such the recovered components are returned back to the susceptible compartment at a given rate $(\omega)$

- The total population is compartmentalized in to four (4) epidemiological classes as shown in figure (1)

\subsection{Model Equation}

The corresponding mathematical model equations are described by a system of ordinary differential equation given below: 


$$
\begin{aligned}
& \frac{d S}{d t}=b N-\frac{\beta S I}{N}+\omega R-\mu S \\
& \frac{d E}{d t}=\frac{\beta S I}{N}-(k+\alpha+\mu) E \\
& \frac{d I}{d t}=k E-(\eta+\tau+\mu+\delta) I \\
& \frac{d R}{d t}=(\eta+\tau) I+\alpha E-(\omega+\mu) R
\end{aligned}
$$

\subsection{Symbols for State Variables}

$$
\begin{array}{ll}
S & \text { Number of susceptible individuals } \\
E & \text { Number of exposed individuals } \\
I & \text { Number of infected individuals } \\
R & \text { Number of recovered individuals } \\
N & \text { Total population }
\end{array}
$$

1.2.4. Symbols for Parameters

$b \quad$ Per capital birth rate of humans

$\mu \quad$ Per capital natural death rate of humans

$\beta \quad$ Transmission rate

$k \quad$ Progression from E to I

$\eta \quad$ Natural recovery from tuberculosis

$\tau \quad$ Recovery due to treatment

$\delta \quad$ Tuberculosis-induced death rate by $I$

$\alpha \quad$ Treatment rate for exposed individuals

$\omega \quad$ Loss (waning) of immunity by recovered individuals.

based on biological considerations, model system (1) will be studied in the following region

$$
=\left\{(S, E, I, R) \in R_{+}^{4}: N \leq \frac{b N}{\mu}\right\}
$$

which can be shown to be positively invariant with respect to the model system (1). 


\section{Disease Free Equilibrium $\left(E_{f}\right)$ and Model Analysis}

The disease free equilibrium state is a steady state solution where there is no disease [24]. To obtained disease free equilibrium, the right hand sides of system model (1) is set to zero and the state variables S, E, I and $\mathrm{R}$ are solved.

$$
\begin{aligned}
& \frac{d S}{d t}=0 \Rightarrow b N-\frac{\beta S I}{N}+\omega R-\mu S=0 \\
& \frac{d E}{d t}=0 \Rightarrow \frac{\beta S I}{N}-(k+\alpha+\mu) E=0 \\
& \frac{d I}{d t}=0 \Rightarrow k E-(\eta+\tau+\mu+\delta) I=0 \\
& \frac{d R}{d t}=0 \Rightarrow(\eta+\tau) I+\alpha E-(\omega+\mu) R=0
\end{aligned}
$$

If $E=0, I=0$, and $R=0$, then equation (3) becomes

$$
S=\frac{b N}{\mu}, E=0, I=0, R=0
$$

Therefore, substituting with $\mathrm{E}=\mathrm{I}=\mathrm{R}=0$, we obtained disease free equilibrium

$$
\left(S^{*}, E^{*}, I^{*}, R^{*}\right)=\left(\frac{b N}{\mu}, 0,0,0\right)
$$

\section{1.. Basic Reproduction Number, Ro}

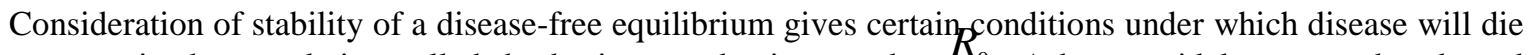
out or stay in the $R_{0}$ pulation called the basic reproduction number, $R_{0}$. A better widely accepted and used method in finding $R_{0}$ that reflect its biological meaning is the next generation operator approach describsd by [16] and subsequently analysed by [ 3]. Using this approach we obtain the basic reproduction number, ${ }_{0}$ of the model system (1) which is the spectral radius $(\rho)$ of the next generation matrix, $K$.

i.e.

$$
R_{0}=\rho K \text {, where } K=F V^{-1}
$$

$$
F=\left(\begin{array}{cc}
0 & \frac{\beta b}{\mu} \\
0 & 0
\end{array}\right)
$$


$V^{-1}=\left(\begin{array}{cc}\frac{1}{(\tau+\eta+\delta+\mu)} & 0 \\ \frac{k}{(k+\alpha+\mu)(\tau+\eta+\delta+\mu)} & \frac{1}{(k+\alpha+\mu)}\end{array}\right)$

$R c=\frac{\beta k b}{\mu(k+\alpha+\mu)(\eta+\tau+\delta+\mu)}$

$R_{o}=\frac{\beta k b}{\mu(k+\mu)(\eta+\delta+\mu)}$

\section{Result and Discussion}

In this section, we do numerical simulation of model system (1) using maple software. The numerical values that we used for the simulation are presented in Table (1). Most of the parameters values in Table (1) are from the literature.

Table 1: Values of Parameters of the Model

\begin{tabular}{|c|c|c|c|}
\hline S/N & Parameters & Value & Source \\
\hline 1 & $b$ & 0.027 & {$[25]$} \\
\hline 2 & $\mu$ & 0.02 year $^{-1}$ & {$[21]$} \\
\hline 3 & $\beta$ & $0.35(0.1-0.6) 0.02$ year $^{-1}$ & {$[22]$} \\
\hline 4 & $\delta$ & 0.3 & {$[21]$} \\
\hline 5 & $\tau$ & $(0-1)$ & Varying \\
\hline 6 & $\alpha$ & $(0-1)$ & Varying \\
\hline 7 & $k$ & 0.025 & {$[23]$} \\
\hline 8 & $\omega$ & 0.4 & {$[20]$} \\
\hline 9 & $\eta$ & 0.2 & {$[21]$} \\
\hline
\end{tabular}

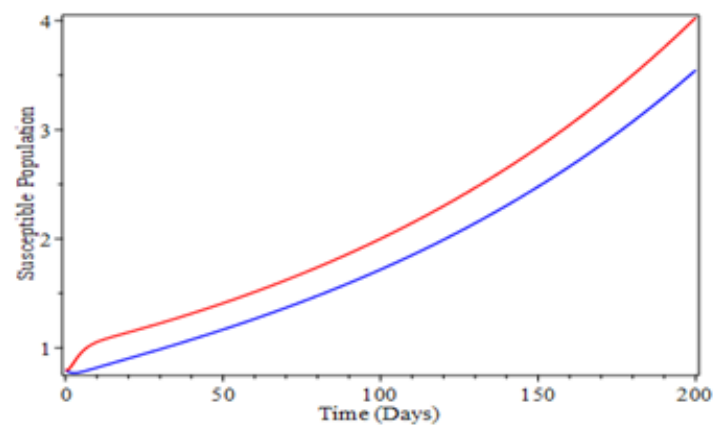

-... no control $=$ with control

Fig 2. The total number of susceptible individuals without any control which gives Rc=1.3889 with control gives Rc=0.0276 
Figure 2 shows the graphical profile of susceptible population without any intervention and in the presence of intervention for the period of 200 days. It can be seen that the number of susceptible individuals decrease without any intervention and increases sharply in the presence of intervention.

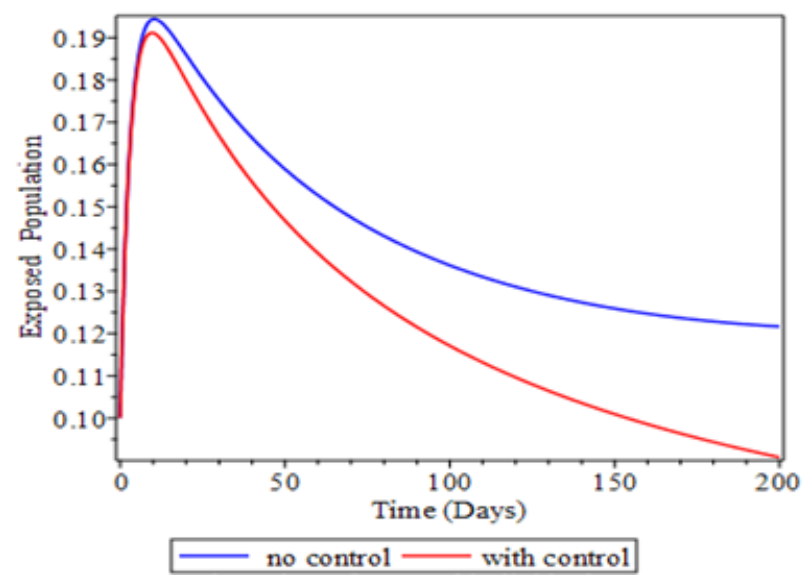

Fig 3. The total number of exposed individuals without any control which gives Rc=1.3889 with control gives Rc=0.0276

Figure 3 shows the numerical simulation of the exposed individuals without control and in the presence of control. It is observed that without control the number of exposed individuals gradually increase and with control the exposed individuals drops to zero.

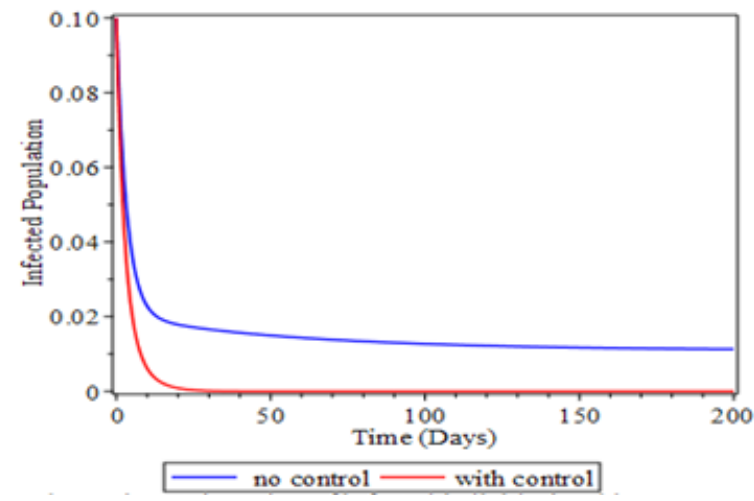

Fig 4. The total number of infected individuals without any control which gives Rc=1.3889 with control gives Rc=0.0276

Figure 4 shows the simulation of infected individuals as a function of time with both absence and presence of control. It can be observed that the number infected individuals decreases very rapidly to zero level and stayed there indicating that there is no more tuberculosis burden and at this time it has been shown in figure 5 that the number of the recovered individuals have gradually increased. 

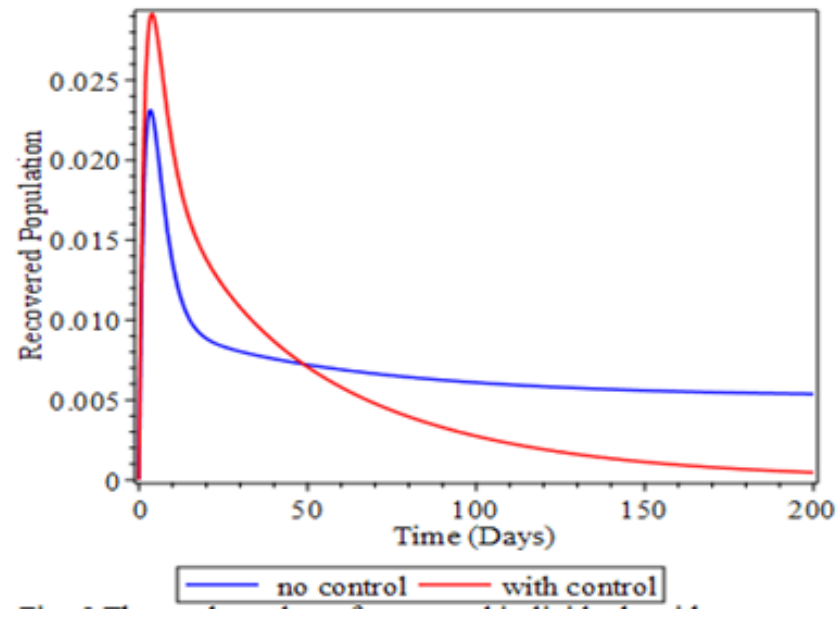

Fig 5. The total number of recovered individuals without any control which gives $\mathrm{Rc}=1.3889$ with control gives $\mathrm{Rc}=0.0276$

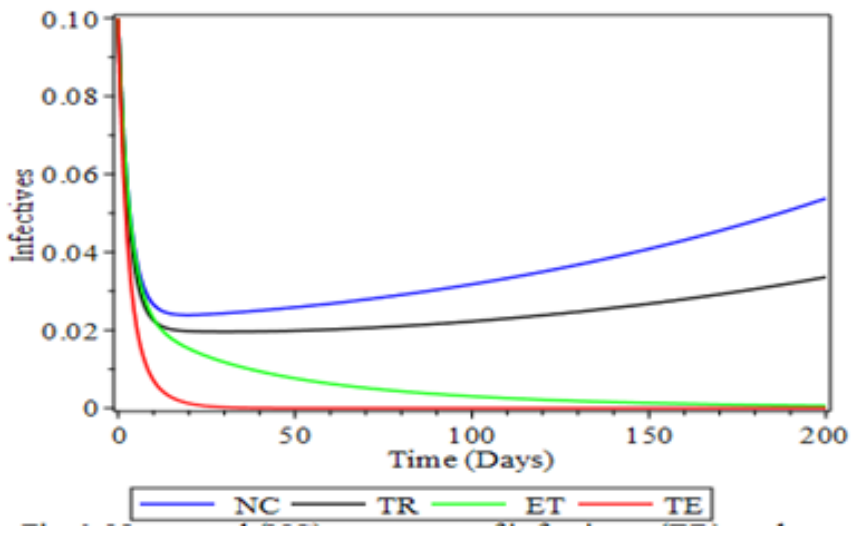

Fig 6. No control(NC), treatment of infectivess(TR), early treatment of latently tuberculosis patient(ET) and both treatment of infectives and early treament of latently tuberculosis patients(TE)

Figure 6 present the dynamics of infected population with four different situation by testing the model without any control, with treatment of infective only, with early therapy of patients with the disease and with both treatment of infective and early therapy of patients.

Rt denote effective basic reproduction number with respect to treatment of infective only while Re represent effective basic reproduction number with respect to early therapy of patients with tuberculosis. 


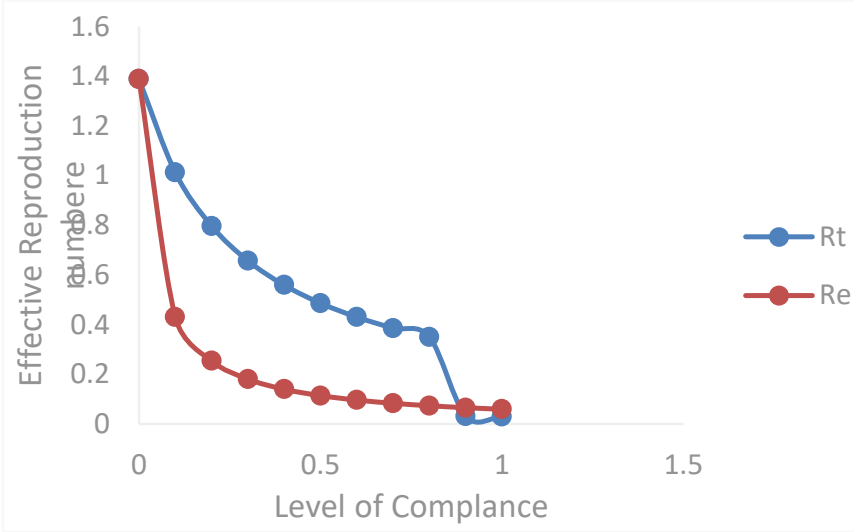

Figure 7 shows the trend of $\mathrm{R}_{\mathrm{t}}$ and $\mathrm{R}_{\mathrm{e}}$ of effective basic reproduction numbers obtained by varying level of compliance from (0-1).

Table 2: Values of effective basic reproduction number with respect to level of complance

\begin{tabular}{|c|c|c|}
\hline $\begin{array}{c}\text { Level of } \\
\text { complance }\end{array}$ & $\mathrm{Rt}$ & $\mathrm{Re}$ \\
\hline 0 & 1.3889 & 1.3889 \\
\hline 0.1 & 1.0135 & 0.431 \\
\hline 0.2 & 0.7979 & 0.2551 \\
\hline 0.3 & 0.6579 & 0.1812 \\
\hline 0.4 & 0.5597 & 0.1404 \\
\hline 0.5 & 0.487 & 0.1147 \\
\hline 0.6 & 0.431 & 0.0969 \\
\hline 0.7 & 0.3866 & 0.0839 \\
\hline 0.8 & 0.3505 & 0.074 \\
\hline 0.9 & 0.0321 & 0.06613 \\
\hline 1 & 0.0295 & 0.0598 \\
\hline
\end{tabular}

\section{Conclusion}

This paper present and studied a deterministic models of tuberculosis infection by incorporating some important factors that plays a significant role in tuberculosis transmission which include vital dynamics, early therapy of patient with tuberculosis and treatment of infective. To considered the effect of early early therapy of latently infected and treatment of infected individuals, figure 2,3,4 and 5 are plotted with presence and absence of control. It is observed that the number of susceptible individuals increase sharply when control are applied and exposed individuals slowly.

Our result reveals that the two (2) controls reduced effective basic reproduction number below the unity. It further show that early therapy of patients with tuberculosis is more effective. And finally obtained simulations results confirm both early therapy of patients with tuberculosis and treatment of infective control the epidemics of tuberculosis, although the two combined intervention offered the most effective. 
There is a need for future research work on the comparing the model with bilinear incidence rate, incorporation of vaccination, public health education, isolation of infected individuals and also to perform sensitivity analysis to know which parameter is more sensitive.

\section{References}

[1] Nyerere N, Luboobi LS, Nkansah-Gyekye Y. Modeling the effect of screening and treatment on the transmission of tuberculosis infections. Mathematical theory and Modeling. 2014;4(7):51-62.

[2] Bhunu CP, Garira W, Mukandavire Z, Zimba M. Tuberculosis transmission model with chemoprophylaxis and treatment. Bulletin of Mathematical Biology. 2008 May 1;70(4):1163-91.

[3] Van den Driessche P, Watmough J. Reproduction numbers and sub-threshold endemic equilibria for compartmental models of disease transmission. Mathematical biosciences. 2002 Nov 1;180(1-2):29-48.

[4] Castillo-Chavez C, Song B. Dynamical models of tuberculosis and their applications. Mathematical biosciences and engineering. 2004 Sep 1;1(2):361-404.

[5] Ugwa KA, Agwu IA. Mathematical Analysis Of The Endemic Equilibrium Of Thetransmission Dynamics Of Tuberculosis. International Journal of Scientific \& Technology Research. 2013 Dec 25;2(12):263-9.

[6] Grange JM, Zumla A. The global emergency of tuberculosis: what is the cause?. The journal of the Royal Society for the Promotion of Health. 2002 Jun;122(2):78-81.

[7] WHO, Report, Global tuberculosis control: epidemiology, strategy, financing. Geneva:World Health Organization; 2009.

[8] Ziv E, Daley CL, Blower S. Potential public health impact of new tuberculosis vaccines. Emerging infectious diseases. 2004 Sep;10(9):1529.

[9] Daniel TM. The history of tuberculosis. Respiratory medicine. 2006 Nov 1;100(11):1862-70.

[10] Bhunu CP, Garira W. A two strain tuberculosis transmission model with therapy and quarantine. Mathematical Modelling and Analysis. 2009 Jan 1;14(3):291-312.

[11] Feng Z, Huang W, Castillo-Chavez C. On the role of variable latent periods in mathematical models for tuberculosis. Journal of dynamics and differential equations. 2001 Apr 1;13(2):425-52.

[12] Liu L, Wang Y. A mathematical study of a TB model with treatment interruptions and two latent periods. Computational and mathematical methods in medicine. 2014;2014.

[13] Maliyoni M, Mwamtobe PM, Hove-Musekwa SD, Tchuenche JM. Modelling the role of diagnosis, treatment, and health education on multidrug-resistant tuberculosis dynamics. ISRN Biomathematics. 2012 Aug 16;2012.

[14] ADELEYE ES. Modelling The impact of BCG vaccines on tuberculosis epidemics. Journal of Mathematical Modelling and Application. 2014 Apr 22;1(9):49-55.

[15] Diekmann O, Heesterbeek JA. Mathematical epidemiology of infectious diseases: model building, analysis and interpretation. John Wiley \& Sons; 2000 Apr 7.

[16] Feng Z, Castillo-Chavez C, Capurro AF. A model for tuberculosis with exogenous reinfection. Theoretical population biology. 2000 May 1;57(3):235-47.

[17] Blower SM, Mclean AR, Porco TC, Small PM, Hopewell PC, Sanchez MA, Moss AR. The intrinsic transmission dynamics of tuberculosis epidemics. Nature medicine. 1995 Aug;1(8):815.

[18] Picon PD, Bassanesi SL, Caramori ML, Ferreira RL, Jarczewski CA, Vieira PR. Risk factors for recurrence of tuberculosis. Jornal brasileiro de pneumologia. 2007 Oct;33(5):572-8.

[19] Dye C, Williams BG. Criteria for the control of drug-resistant tuberculosis. Proceedings of the National Academy of Sciences. 2000 Jul 5;97(14):8180-5.

[20] Dye C, Scheele S, Dolin P, Pathania V, Raviglione MC. for the WHO Global Surveillance and Monitoring Project. Global burden of tuberculosis: estimated incidence, prevalence, and mortality by country. Jama. 1999 Aug 18;282(7):677-86. 
[21] Kuta FA, Somma SA, Tech M. Local Stability Analysis of a Tuberculosis Model incorporating Extensive Drug Resistant Subgroup FY Eguda, Ph. D.; NI Akinwande Ph. D. 2; S. Abdulrahman Ph. D. 2.

[22] Ronoh M, Jaroudi R, Fotso P, Kamdoum V, Matendechere N, Wairimu J, Auma R, Lugoye J. A mathematical model of tuberculosis with drug resistance effects. Applied Mathematics. 2016 Jul 25;7(12):1303.

[23] Sensitivity analysis of the parameters of a mathematical model of Hepatitis B virus transmission.

[24] Sulayman F. Modelling and analysis of the spread of cholera disease in Nigeria with environmental control. Research thesis, 2014 - psasir.upm.edu.my.

[25] Rohaeti E, Wardatun S, Andriyati A. Stability Analysis Model of Spreading and Controlling of Tuberculosis. Applied Mathematical Sciences. 2015;9(52):2559-66.

[26] Kar TK, Mondal PK. Global dynamics of a tuberculosis epidemic model and the influence of backward bifurcation. Journal of Mathematical Modelling and Algorithms. 2012 Dec 1;11(4):433-59.

[27] World Health Organization. Global tuberculosis report 2013. World Health Organization; 2013.

\section{Authors’ Profiles}

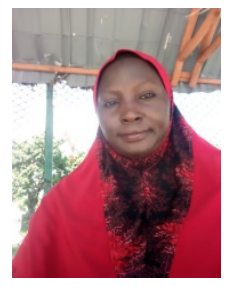

Mrs Sulayman Fatima, Department of Mathematical Sciences, Faculty of Applied and Natural Science, Ibrahim Badamasi Babangida University Lapai, Niger State, Nigeria.

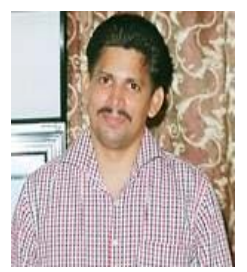

\section{Amit Mishra (PhD):}

Dr. Amit Mishra is an Assistant Professor in the Department of Computer Science, at Baze University, Abuja, Nigeria. His current research interests include: Software Engineering, Reverse Engineering, Software maintenance, web development, mobile app.

How to cite this paper: Sulayman Fatima, Amit Mishra," A SEIRS Model of Tuberculosis Infection Model with Vital Dynamics, Early Treatment for Latent Patients and Treatment of Infective", International Journal of Mathematical Sciences and Computing(IJMSC), Vol.6, No.3, pp.42-52, 2020. DOI: 10.5815/ijmsc.2020.03.05 